\title{
Investigation of the Carbochlorination Process for Conversion of Cerium and Neodymium Oxides into Their Chlorides
}

\author{
A. Anderson ${ }^{1}$ - B. Mishra ${ }^{1}$
}

Published online: 24 July 2015

(C) The Minerals, Metals \& Materials Society (TMS) 2015

\begin{abstract}
This study focuses on evaluating the conversion of cerium oxide and neodymium oxide into their chlorides through the carbochlorination process. The experiments were completed inside a quartz reactor, and the $\%$ conversion was determined by performing a water leach to dissolve the soluble chloride phases present and leave behind the insoluble unreacted oxide and oxychloride phases. The process parameters chosen for this investigation were temperature, time, chlorine gas concentration, and carbon-to-rare earth oxide ratio. A rate curve was generated for both the cerium oxide and neodymium oxide carbochlorination processes. These curves showed that reactions had a significant dependence on time with $4 \mathrm{~h}$ being the optimal reaction time for both processes. Statistical modeling and optimization was also performed through the use of Stat-Ease Design-Expert $8^{\circledR}$ software. This analysis showed that temperature had the most significant effect on the degree of reaction achieved for both processes. The reaction products were also subjected to $\mathrm{X}$-ray diffraction analysis to verify the degree of reaction determination method as well as to determine whether any intermediate phases occurred during the carbochlorination process.
\end{abstract}

The contributing editor for this article was I. Sohn.

B. Mishra

bmishra@mines.edu

A. Anderson

alaander@mines.edu

1 Materials and Metallurgical Engineering, Colorado School of Mines, 1500 Illinois Street, Golden, CO 80401, USA
Keywords Carbochlorination - Cerium oxide . Neodymium oxide $\cdot$ Rare earth metals

\section{Introduction}

The rare earth elements are generally defined as the fifteen lanthanide elements in addition to scandium $(\mathrm{Sc})$ and yttrium (Y). Although, for practical engineering applications, scandium and promethium are excluded from this classification because scandium is scarcely found in nature and promethium is a radioactive element [1]. The remaining rare earth elements in the group have become vital to many modern technologies, which include electronics, clean energy, and national defense applications [2]. Despite what the name suggests, these elements are not "rare" yet they can be challenging to process and are subject to supply chain disruptions due to various economic and political events. Many of the rare earth elements are used in their metal forms, yet there is a lack of knowledge about available commercial processes for metal production because only small amounts of these metals are produced outside China [3].

Traditionally, there are three primary methods practiced for producing pure rare earth metals from compounds. These three methods are (1) reduction of anhydrous chlorides and fluorides, (2) direct reduction of rare earth oxides, and (3) fused salt electrolysis of rare earth chlorides or oxide-fluoride mixtures [4]. Rare earth oxides are the typical starting material for conversion into metals because they are the most common products of ore processing and separation operations. Therefore, in the case of the metal production methods that involve molten salt electrolysis or the reduction of rare earth halides, the conversion of rare earth oxides into their respective halides is a necessary step 
that allows for ease of production [5]. One viable option for this conversion is through a carbohalogenation reaction which can be performed to produce either chlorides or fluorides.

This study focuses on evaluating the conversion of cerium oxide and neodymium oxide to their respective chlorides through the carbochlorination reaction in order to better understand and to optimize the steps involved in rare earth metal production. The carbochlorination process is one in which a metal oxide is converted into the corresponding metal chloride in the presence of carbon and chlorine gas. From a thermodynamic standpoint, the carbon is used as a reducing agent and lowers the necessary reaction temperature [6]. In terms of kinetics, it has been shown that direct contact between the metal oxides and the carbon is not necessary for effective chlorination, which has led to the conclusion that carbochlorination reaction happens through gaseous intermediates. Carbon is thought to favor the formation of these intermediates because it has catalytic activity sites where the formation of highly reactive gas intermediates is possible. Phosgene $\left(\mathrm{COCl}_{2}\right)$, monatomic chlorine, and carbon tetrachloride $\left(\mathrm{CCl}_{4}\right)$ have all been proposed as the gaseous intermediates [7].

The subsequent goals of this research are to dissolve the product rare earth chlorides in low-temperature molten salt electrolytes for the electrolytic production of rare earth metals. Therefore, the conversion efficiencies have been measured in excess chlorine gas and carbon addition in an unstirred reactor under flowing gas as a solid-gas reaction.

\section{Experimental}

\section{Thermodynamic Considerations}

HSC Chemistry 5.1 software was used to first perform a preliminary thermodynamic analysis to determine the most favorable reactions for both carbochlorination systems for the temperature range under evaluation. The proposed reactions based on the thermodynamic analysis of the carbochlorination process of the two rare earth oxides are as follows [8]:

$T<700{ }^{\circ} \mathrm{C}$

$\mathrm{CeO}_{2}+\mathrm{C}+1.5 \mathrm{Cl}_{2}(\mathrm{~g}) \rightarrow \mathrm{CeCl}_{3}+\mathrm{CO}_{2}(\mathrm{~g})$

$\mathrm{Nd}_{2} \mathrm{O}_{3}+1.5 \mathrm{C}+3 \mathrm{Cl}_{2}(\mathrm{~g}) \rightarrow 2 \mathrm{NdCl}_{3}+1.5 \mathrm{CO}_{2}(\mathrm{~g})$

$T>700{ }^{\circ} \mathrm{C}$

$\mathrm{CeO}_{2}+2 \mathrm{C}+1.5 \mathrm{Cl}_{2}(\mathrm{~g}) \rightarrow \mathrm{CeCl}_{3}+2 \mathrm{CO}(\mathrm{g})$

$\mathrm{Nd}_{2} \mathrm{O}_{3}+3 \mathrm{C}+3 \mathrm{Cl}_{2}(\mathrm{~g}) \rightarrow 2 \mathrm{NdCl}_{3}+3 \mathrm{CO}(\mathrm{g})$

The thermodynamic analysis showed that at temperatures above $700{ }^{\circ} \mathrm{C}$ the primary off gas would switch from
$\mathrm{CO}_{2}$ to $\mathrm{CO}$ thereby requiring more carbon for the conversion.

HSC Chemistry 5.1 software was also used to investigate the possibility of the formation of intermediate oxychloride phases for both carbochlorination systems. Figure 1 shows phase stability diagrams for the $\mathrm{Ce}-\mathrm{O}-\mathrm{Cl}$ system, and Fig. 2 shows phase stability diagrams for the $\mathrm{Nd}-\mathrm{O}-\mathrm{Cl}$ system at two different temperatures. The $x$-axis for all the diagrams was converted from the $\log \mathrm{pO}_{2}(\mathrm{~g})$ to the equivalent $\log \mathrm{pCO}_{2}(\mathrm{~g})$ scale assuming a carbon activity of one. The boxes on the diagrams indicate the reasonable operating range for this study for each system. The phase stability diagrams for the $\mathrm{Ce}-\mathrm{O}-\mathrm{Cl}$ system also show that there is a direct boundary between the $\mathrm{CeO}_{2}$ and the $\mathrm{CeCl}_{3}$ within the reasonable operating range. This implies from a thermodynamic standpoint that the $\mathrm{CeO}_{2}$ will not have to go through an intermediate phase for its conversion to $\mathrm{CeCl}_{3}$. On the other hand, the phase stability diagrams for the $\mathrm{Nd}-\mathrm{O}-\mathrm{Cl}$ system show that there is no direct boundary between the $\mathrm{Nd}_{2} \mathrm{O}_{3}$ phase and the $\mathrm{NdCl}_{3}$ phase. This indicates that the $\mathrm{Nd}_{2} \mathrm{O}_{3}$ must convert to the intermediate $\mathrm{NdOCl}$ phase before making a full conversion to the $\mathrm{NdCl}_{3}$ phase at both reaction temperatures. Therefore, from a thermodynamic standpoint, the oxychloride phase will play a much larger role in the neodymium oxide carbochlorination reaction than the cerium oxide carbochlorination reaction.

\section{Materials}

The rare earth oxide powders used for the carbochlorination experiments were procured from Alfa Aesar. The cerium oxide powder used had a purity level of $99.5 \%$, and the neodymium oxide used had a purity level of $99.9 \%$. The average particle size for the cerium oxide was $42 \mu \mathrm{m}$ and the $\mathrm{P}_{80}$ was $68.5 \mu \mathrm{m}$. The average particle size of neodymium oxide was $14.5 \mu \mathrm{m}$ and the $\mathrm{P}_{80}$ was $20.9 \mu \mathrm{m}$. High-purity activated carbon was purchased from Sigma Aldrich to be used as the carbon source in the carbochlorination experiments. The two input gases used were industrial-grade argon and a mixture of $25 \%$ chlorine and $75 \%$ argon gas.

\section{Experimental Setup}

Figure 3 shows a schematic of the experimental setup used for this study. The carbochlorination experiments were carried out inside fume-hood to ensure safe handling of any harmful off gases. The two input gas tanks were placed next to the hood and the lines for each tank were routed up into a rotameter, so the flow could be adjusted and maintained. The body of the reactor was made entirely of quartz and the lid was made of Pyrex to avoid any issues 

for the $\mathrm{Ce}-\mathrm{O}-\mathrm{Cl}$ system at a $400{ }^{\circ} \mathrm{C}$ and b $750{ }^{\circ} \mathrm{C}$ with the $x$-axis converted from the $\log$ $\mathrm{pO}_{2}(\mathrm{~g})$ to the equivalent $\mathrm{Log}$ $\mathrm{pCO}_{2}(\mathrm{~g})$ scale [8]
Fig. 1 Phase stability diagrams
Fig. 2 Phase stability diagrams for the $\mathrm{Nd}-\mathrm{O}-\mathrm{Cl}$ system at a $400{ }^{\circ} \mathrm{C}$ and $\mathbf{b} 750{ }^{\circ} \mathrm{C}$ with the $x$-axis converted from the $\log$ $\mathrm{pO}_{2}(\mathrm{~g})$ to the equivalent $\mathrm{Log}$ $\mathrm{pCO}_{2}(\mathrm{~g})$ scale [8]
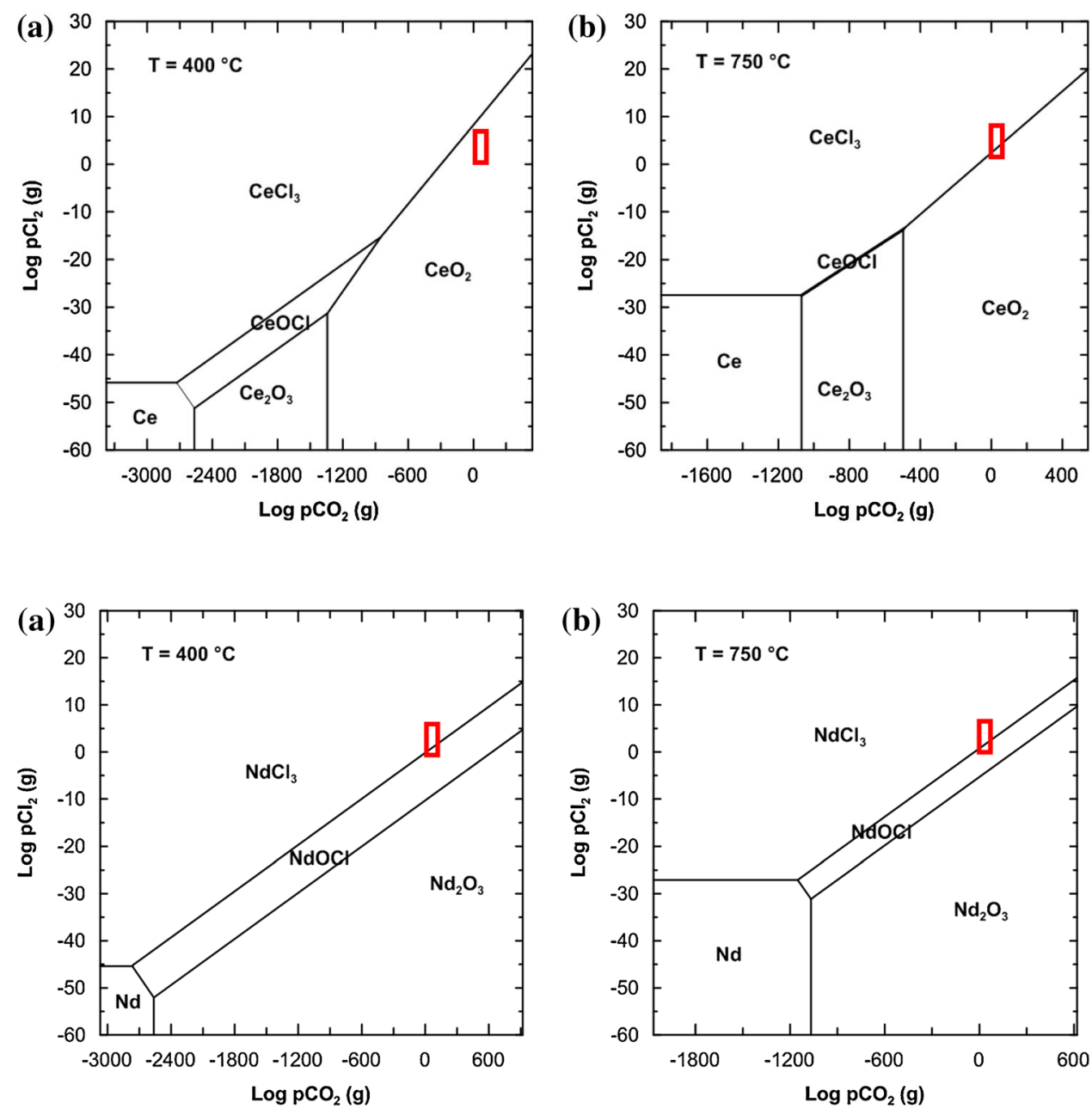

Fig. 3 Schematic diagram showing the individual components of the experimental setup used for the carbochlorination experiments

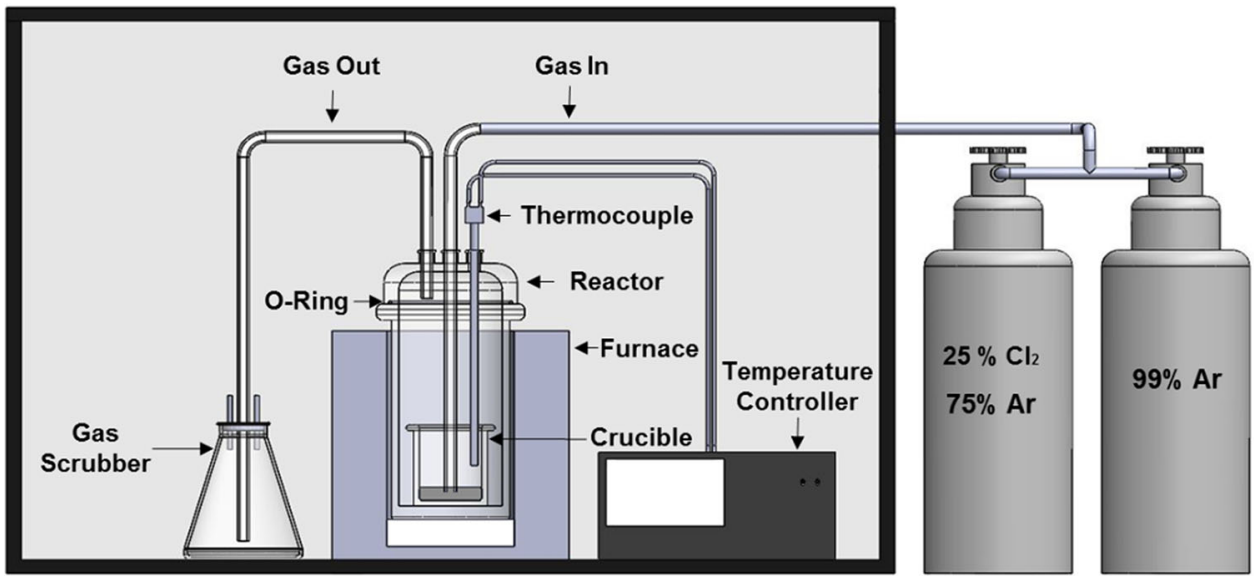

associated with metallic corrosion due to the high-temperature chlorine gas atmosphere. The quartz body was placed inside of a Lindberg box furnace for heating, and the reactor was sealed using a horseshoe clamp and a Viton O-ring. Viton was chosen because it is chemically inert and resistant to degradation in a chlorine atmosphere, but it could not withstand the temperatures necessary for the carbochlorination reaction. For this reason, the reactor was designed to stick up out of the furnace so that the O-ring could remain away from the heated zone. The lid of the vessel was purchased from Pyrex and equipped with three ports which housed Teflon bushings for $1 / 4$ inch tubing. 
These ports were used for the gas inlet, the gas outlet, and for thermocouple access. The gas outlet line was routed into a caustic soda scrubbing solution to neutralize any excess chlorine gas and other by-product gases [9]. The sample was placed inside a quartz crucible, which sat at the bottom of the reactor during testing.

\section{Procedure}

The overall procedure for the carbochlorination experiments remained constant even with varying process parameters. The rare earth oxide and carbon sample was weighed, recorded, and mixed in the quartz sample crucible. The sample crucible was then placed inside the quartz vessel and the vessel was tightly sealed. Argon gas was introduced into the system while heating the reactor to the desired temperature at a ramp rate of $300{ }^{\circ} \mathrm{C} / \mathrm{h}$. Once the desired temperature was reached, the system was allowed to stabilize for $30 \mathrm{~min}$ before chlorine gas was introduced. After the stabilization period was complete, the flow of argon was turned off and chlorine gas mixture was introduced at the appropriate flow rate for the test. When the test was complete, the furnace was shut off and argon gas flowed into the system during the cooling process. Once cooled, the sample was removed from the reactor, weighed, and stored for analysis.

An argon shield was used to heat and cool the sample in order to eliminate any reversal of the carbochlorination reaction due to rare earth elements' great affinity for oxygen and to minimize any absorption of water from the atmosphere by the rare earth oxides or chloride.

\section{Degree of Reaction Determination}

The degree of reaction for this study was defined as the percentage of rare earth oxides that were converted to rare earth chlorides during each carbochlorination reaction. The degree of reaction for each experiment was determined by exploiting the differences in the solubility between the rare earth oxides and rare earth chlorides in water. The rare earth oxides studied are insoluble in water, whereas their corresponding chlorides have high solubility in water [10]. Therefore, to determine the amount of oxide that was converted to chloride, a $10 \mathrm{~g}$ sample of the reacted powder mixture was mixed with $100 \mathrm{~mL}$ of deionized water and stirred for $8 \mathrm{~h}$. The solution was then subjected to two stages of filtration, a coarse stage and a fine stage. The coarse stage used filter paper with a particle size retention of $20-25 \mu \mathrm{m}$, and the fine stage used filter paper with a particle size retention $0.8 \mu \mathrm{m}$. Both stages were performed under vacuum assistance. The retained solids were dried and weighed, and the $\%$ conversion value was calculated using Eq. 5:
$\%$ Conversion

$$
=\frac{[\text { Original sample mass }]-\left[(\Delta \mathrm{m})_{\text {coarse }}+(\Delta \mathrm{m})_{\text {fine }}\right]}{\text { Original sample mass }} \text {. }
$$

\section{Design of Experiments}

The aim of the carbochlorination experiments was not only to prove the feasibility of the reaction, but also to optimize the process parameters involved. In order to achieve this objective, the design of experiments was broken into three parts: generation of a rate curve to assess the kinetics of the reaction, input material optimization through the use of statistical software, and phase identification through X-ray diffraction (XRD) analysis. The rate curve generated for the carbochlorination reaction of each rare earth oxide was used to determine the optimal reaction time as well as the rate-controlling mechanism. Phase identification through XRD was used to verify the degree of reaction determination method as well as to investigate the presence of intermediate phases that could have occurred during the carbochlorination process. The four process parameters chosen for evaluation were time, temperature, chlorine gas concentration, and carbon-to-rare earth oxide ratio. The remaining three process parameters were evaluated through the use of a statistical modeling and optimization software called Stat-Ease Design-Expert $8^{\circledR}$. A three-factor twolevel full factorial experimental design with three midpoints was utilized for this analysis. Tables 1 and 2 list the lower and upper limits for each process parameter tested for the cerium oxide and neodymium oxide carbochlorination study, respectively. The 0 and $100 \%$ excess denotes the quantity related to the stoichiometric amount corresponding to Eqs. 1 and 2.

\section{Results and Discussion}

\section{Carbochlorination Reaction Rate Curves}

Figure 4 shows the rate curves generated for the cerium oxide and neodymium oxide carbochlorination reactions. Each test for this curve used $100 \%$ excess carbon and $100 \%$ excess chlorine gas according to Eqs. 1 and 2 at a temperature of $750{ }^{\circ} \mathrm{C}$. In both cases, \% conversion values achieved were greatly affected by the reaction time and the degree of conversion increased steadily between 1 and $4 \mathrm{~h}$. A plateau in the chloride conversion occurred between 4 and $6 \mathrm{~h}$ for both reactions. The $\%$ conversion value achieved for the cerium oxide carbochlorination reaction at $4 \mathrm{~h}$ was $92.3 \%$ and at $6 \mathrm{~h}$ was $95.1 \%$. For the neodymium oxide carbochlorination reaction, the 4 -h test produced a $\%$ 
Table 1 Lower and upper limits of the process parameters tested in the cerium oxide carbochlorination experiments

Table 2 Lower and upper limits of the process parameters tested in the neodymium oxide carbochlorination experiments

\begin{tabular}{lll}
\hline Process parameter & Lower limit & Upper limit \\
\hline Temperature & $400{ }^{\circ} \mathrm{C}$ & $750{ }^{\circ} \mathrm{C}$ \\
Chlorine gas concentration & $9.6 \mathrm{~L}(0 \%$ excess $)$ & $19.2 \mathrm{~L}(100 \%$ excess $)$ \\
$\mathrm{C}: \mathrm{CeO}_{2}$ & $0.070 \mathrm{~g} / \mathrm{g}(0 \%$ excess $)$ & $0.139 \mathrm{~g} / \mathrm{g}(100 \%$ excess $)$ \\
\hline
\end{tabular}

\begin{tabular}{lll}
\hline Process parameter & Lower limit & Upper limit \\
\hline Temperature & $400{ }^{\circ} \mathrm{C}$ & $750{ }^{\circ} \mathrm{C}$ \\
Chlorine gas concentration & $9.8 \mathrm{~L}(0 \%$ excess $)$ & $19.7 \mathrm{~L}(100 \%$ excess $)$ \\
$\mathrm{C}: \mathrm{Nd}_{2} \mathrm{O}_{3}$ & $0.054 \mathrm{~g} / \mathrm{g}(0 \%$ excess $)$ & $0.107 \mathrm{~g} / \mathrm{g}(100 \%$ excess $)$ \\
\hline
\end{tabular}

Fig. 4 Rate curve for the a cerium oxide carbochlorination reaction and b neodymium oxide carbochlorination reaction showing test results between 1 and $6 \mathrm{~h}$

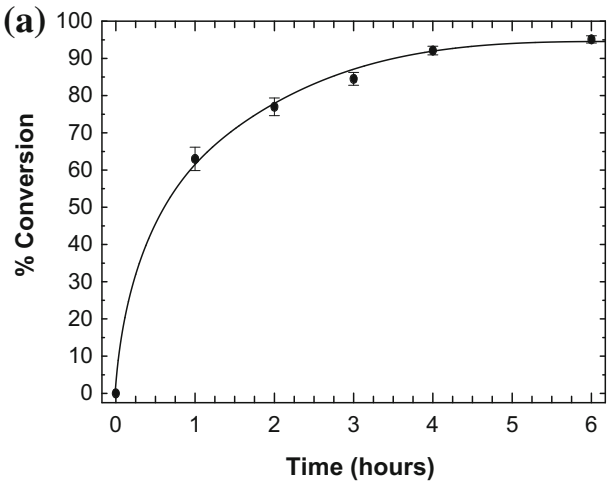

conversion value of $87.4 \%$ and the 6 -h test produced a $\%$ conversion value of $89.9 \%$. The optimal time for both the cerium oxide and neodymium oxide carbochlorination reactions was taken to be $4 \mathrm{~h}$ since little conversion was gained for a reaction time of $6 \mathrm{~h}$.

The rate-controlling mechanism for each reaction was determined by utilizing the heterogeneous rate expressions for fluid-solid reactions based on the shrinking-core model. To perform the analysis, it was assumed that the time for complete reaction, (Equation), was $6 \mathrm{~h}$ for both carbochlorination reactions since the trend from the rate curve indicated that little to no conversion would be gained from an increase in reaction time. Therefore, the conversion at $6 \mathrm{~h}$ for both cerium oxide and neodymium oxide conversion was taken as the maximum, and the tests on the rate curve were normalized according to this value. The resulting normalized conversion values were then used in the rate expressions shown in Table 3 [11]. Figure 5a shows the rate expressions plotted against equation for a constant-sized particle under pore diffusion control, fluid film control, and chemical control for the cerium oxide carbochlorination reaction. The fluid film rate expression did not produce a linear set of data, but the pore diffusion and chemical rate expressions both produced data sets that were fairly linear. The pore diffusion-controlled rate expression produced a function that was slightly more linear than the chemical-controlled rate expression with an $R^{2}$ of 0.99 versus an $R^{2}$ of 0.97 , respectively.

Figure 5b shows the rate expressions plotted against (Equation) for a constant-sized particle under pore diffusion control, fluid film control, and chemical control for the neodymium oxide carbochlorination reaction. The rate expression data for the neodymium oxide carbochlorination reaction look very similar to those for the cerium oxide carbochlorination reaction. The fluid film rate expression did not produce a linear set of data, but the pore diffusion and chemical rate expressions both produced data sets that were fairly linear. The pore diffusion-controlled rate

Table 3 Conversion-time expressions for the shrinking-core model for spherical particles of unchanging size [11]

\begin{tabular}{llr}
\hline Film diffusion control & Ash diffusion control & Reaction control \\
\hline$\frac{t}{\tau}=X_{\mathrm{B}}$ & $\frac{t}{\tau}=1-3\left(1-X_{\mathrm{B}}\right)^{\frac{2}{3}}+2\left(1-X_{\mathrm{B}}\right)$ & $\frac{t}{\tau}=1-\left(1-X_{\mathrm{B}}\right)^{\frac{1}{3}}$ \\
\hline
\end{tabular}


Fig. 5 Fractional time for complete conversion of the a cerium oxide and b neodymium oxide by the carbochlorination reaction plotted against the progress of the reaction according to the various rate-controlling mechanisms

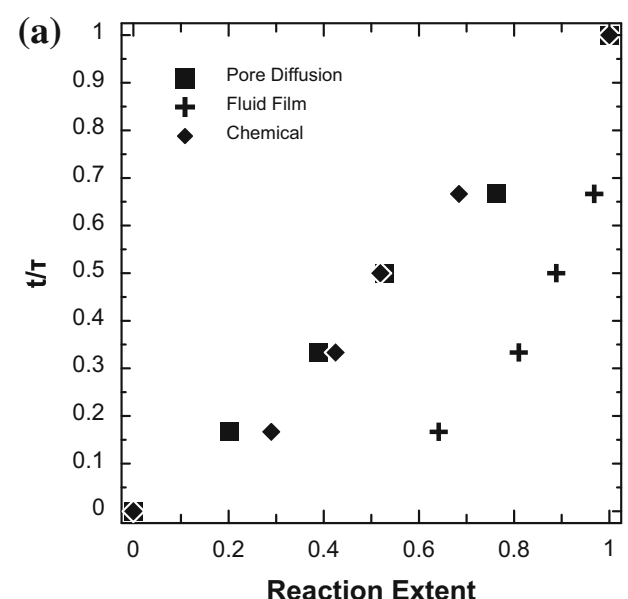

expression produced a function that was slightly more linear than the chemical-controlled rate expression with an $R^{2}$ of 0.95 versus an $R^{2}$ of 0.93 , respectively. In case of both reactions, the kinetic results are too close to conclude whether or not the reaction is under chemical or pore diffusion control. The results of this study could indicate that the carbochlorination reaction of these oxide particles is under a mixed control, but further testing should be done to determine the controlling mechanism with more certainty.

\section{Process Parameter Optimization}

Tables 4 and 5 show, respectively, the cerium oxide and neodymium oxide carbochlorination results ordered from the lowest to the highest \% conversion tests for the statistical portion of the studies utilizing a three-factor twolevel full factorial experimental design with three midpoints order. All of these experiments were performed at a reaction time of $4 \mathrm{~h}$ which was determined from the rate

Table 4 The cerium oxide carbochlorination full factorial design of experiment test results

\begin{tabular}{lllrl}
\hline Test \# & $\mathrm{C}: \mathrm{CeO}_{2}(\mathrm{~g} / \mathrm{g})$ & Temperature $\left({ }^{\circ} \mathrm{C}\right)$ & $\mathrm{Cl}_{2}(\mathrm{~L})$ & $\%$ Conversion \\
\hline 1 & 0.070 & 400 & 9.6 & $16.7 \pm 1.2$ \\
8 & 0.070 & 400 & 19.2 & $18.4 \pm 1.3$ \\
5 & 0.139 & 400 & 9.6 & $21.5 \pm 2.4$ \\
4 & 0.139 & 400 & 19.2 & $24.5 \pm 2.6$ \\
2 & 0.070 & 750 & 9.6 & $37.3 \pm 1.8$ \\
3 & 0.105 & 575 & 14.4 & $51.3 \pm 2.6$ \\
9 & 0.105 & 575 & 14.4 & $51.6 \pm 2.6$ \\
7 & 0.105 & 575 & 14.4 & $52.8 \pm 2.6$ \\
11 & 0.070 & 750 & 19.2 & $65.1 \pm 1.7$ \\
6 & 0.139 & 750 & 9.6 & $65.3 \pm 3.0$ \\
10 & 0.139 & 750 & 19.2 & $92.3 \pm 1.2$ \\
\hline
\end{tabular}

curves to the optimal time for conversion for both reactions.

The maximum $\%$ conversion achieved in the statistical portion of cerium oxide carbochlorination study was $92.3 \%$ and the minimum $\%$ conversion achieved was $16.7 \%$. The maximum $\%$ conversion achieved for the statistical portion of neodymium oxide carbochlorination study was $87.4 \%$ and the minimum $\%$ conversion achieved was $15.6 \%$. The ranges of experimental results provided an optimal spread of data for statistical analysis and modeling, which was performed through the use of Stat-Ease Design-Expert $8^{\circledR}$ software.

The Stat-Ease analysis showed that maximum conversions were achieved at the upper limit of all of the process parameters studied for both the cerium oxide and neodymium oxide carbochlorination studies. The highest \% conversion values found for both studies were the same as those found for the 4-h rate curve test. The operating window for the carbochlorination reaction of both cerium

Table 5 The neodymium oxide carbochlorination full factorial design of experiment test results

\begin{tabular}{lllcl}
\hline Test \# & $\mathrm{C}: \mathrm{CeO}_{2}(\mathrm{~g} / \mathrm{g})$ & Temperature $\left({ }^{\circ} \mathrm{C}\right)$ & $\mathrm{Cl}_{2}(\mathrm{~L})$ & $\%$ Conversion \\
\hline 5 & 0.053 & 400 & 19.67 & $11.7 \pm 1.1$ \\
1 & 0.053 & 400 & 9.8 & $15.6 \pm 1.1$ \\
2 & 0.107 & 400 & 9.8 & $38.6 \pm 2.3$ \\
9 & 0.080 & 575 & 14.75 & $40.0 \pm 1.9$ \\
3 & 0.053 & 750 & 9.8 & $41.2 \pm 1.7$ \\
10 & 0.080 & 575 & 14.75 & $41.5 \pm 1.9$ \\
11 & 0.080 & 575 & 14.75 & $41.6 \pm 1.9$ \\
6 & 0.107 & 400 & 19.67 & $41.9 \pm 2.4$ \\
4 & 0.107 & 750 & 9.8 & $46.5 \pm 2.8$ \\
7 & 0.053 & 750 & 19.67 & $54.6 \pm 1.6$ \\
8 & 0.107 & 750 & 19.67 & $87.4 \pm 1.5$ \\
\hline
\end{tabular}


oxide and neodymium oxide was shown to be quite small with the amounts of conversion achieved dropping off rapidly with decreased temperature. This result indicated that the reaction temperature was the most significant in the carbochlorination process.

The relationship between all three process parameters was observed from various 3D response surfaces that were generated by the Stat-Ease software. Figures 6 and 7 show response surface graphs generated for both carbochlorination studies where chlorine gas concentration $(\mathrm{L})$ is on the $x$-axis, carbon-to-rare earth oxide ratio $(\mathrm{g} / \mathrm{g})$ is on the $y$ axis, and $\%$ conversion is on the $z$-axis. Figure 6 a shows the results for the cerium oxide carbochlorination study where the temperature was held constant at $400{ }^{\circ} \mathrm{C}$. This response surface is relatively flat with little change in $\%$ conversion achieved between the lower and upper limits of both process parameters of carbon and chlorine gas content. Figure $6 \mathrm{~b}$ shows the results for the cerium oxide carbochlorination study where the temperature is held constant at $750{ }^{\circ} \mathrm{C}$. In this case, the degree of conversion achieved is heavily dependent on both the amount of chlorine gas and carbon used in the system. These results indicate that the relationship between the chlorine gas content and carbon content was important for large conversion values, but this relationship was only observed at high temperatures.

Figure $7 \mathrm{a}$ shows the results for the neodymium oxide carbochlorination study where the temperature was held constant at $400{ }^{\circ} \mathrm{C}$. This response surface is not as flat as it was for cerium oxide carbochlorination study, but rather shows that the reaction has a great dependence on the carbon-to-neodymium oxide ratio even at low temperatures. The reaction did not show any influence from chlorine gas content at the lower temperatures. Figure $7 \mathrm{~b}$ shows the results for the neodymium oxide carbochlorination study where temperature was held constant at $750{ }^{\circ} \mathrm{C}$. In this case, the degree of conversion achieved was dependent on both the amount of chlorine gas and carbon used in the system just as in the cerium oxide carbochlorination study.

\section{Phase Identification}

XRD was used to identify the phases present in the cerium oxide and neodymium oxide carbochlorination test samples. The XRD patterns for two representative samples from each study are presented.
Fig. $63 \mathrm{D}$ response surface graphs generated by the StatEase software for the cerium oxide carbochlorination model showing a the case where the temperature is held constant at $400{ }^{\circ} \mathrm{C}$ and $\mathbf{b}$ the case where the temperature is held constant at $750{ }^{\circ} \mathrm{C}$
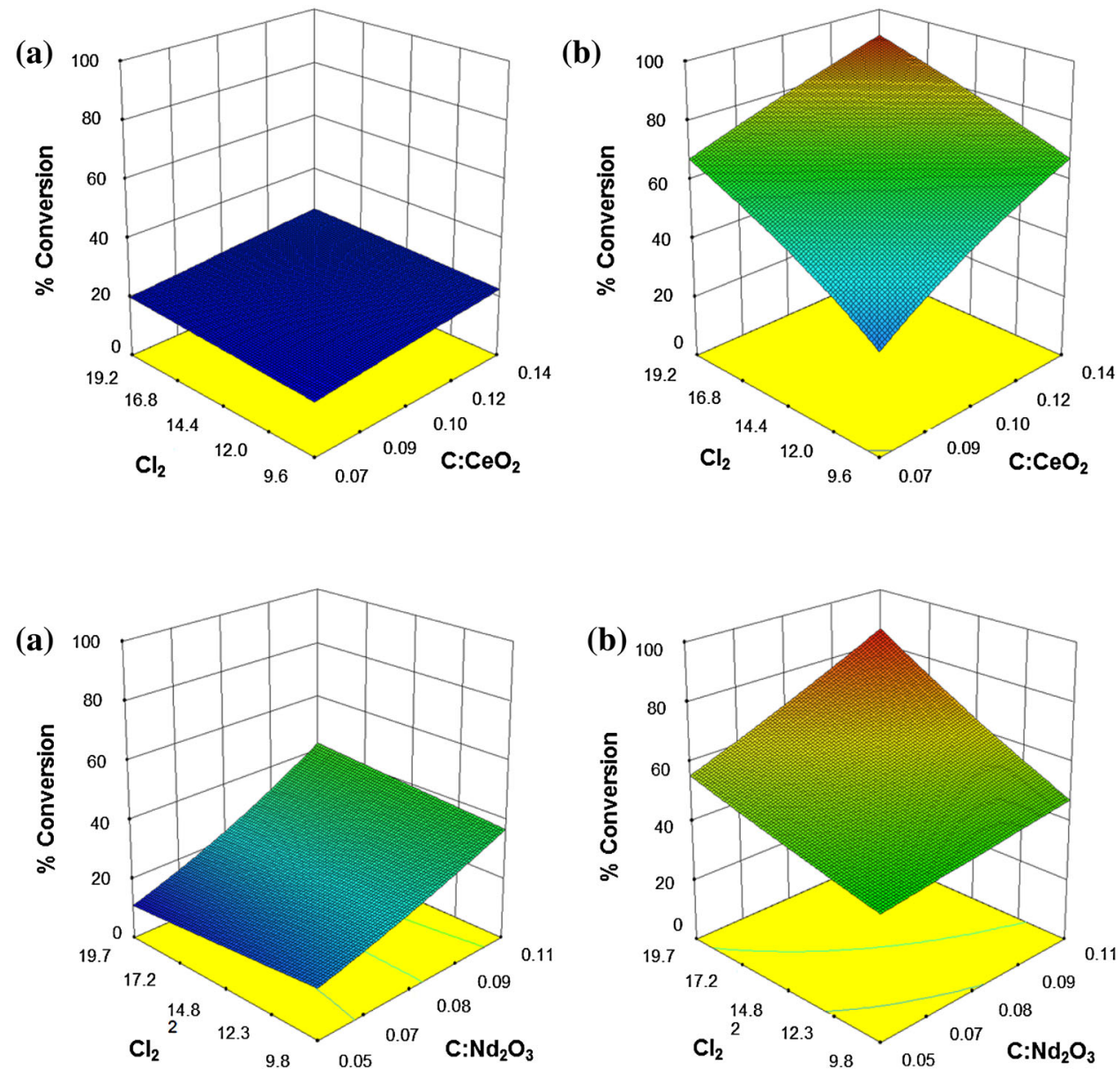

Fig. 7 3D response surface graphs generated by the StatEase software for the neodymium oxide carbochlorination model showing a the case where the temperature is held constant at $400{ }^{\circ} \mathrm{C}$ and $\mathbf{b}$ the case where the temperature was held constant at $750{ }^{\circ} \mathrm{C}$ 
Fig. 8 XRD patterns for the lowest $\%$ conversion sample in the cerium oxide a Before the water leach and

b after the water leach carbochlorination experiments.
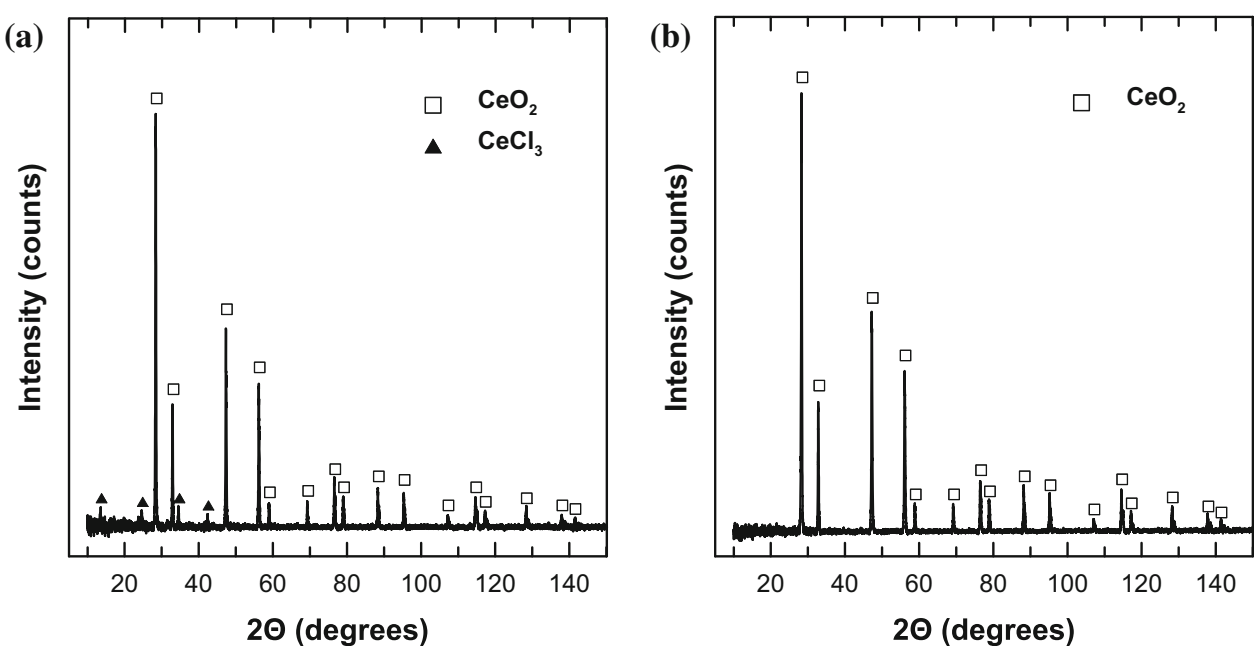

Fig. 9 XRD patterns for the highest $\%$ conversion sample in the cerium oxide carbochlorination experiments. a Before the water leach and b after the water leach

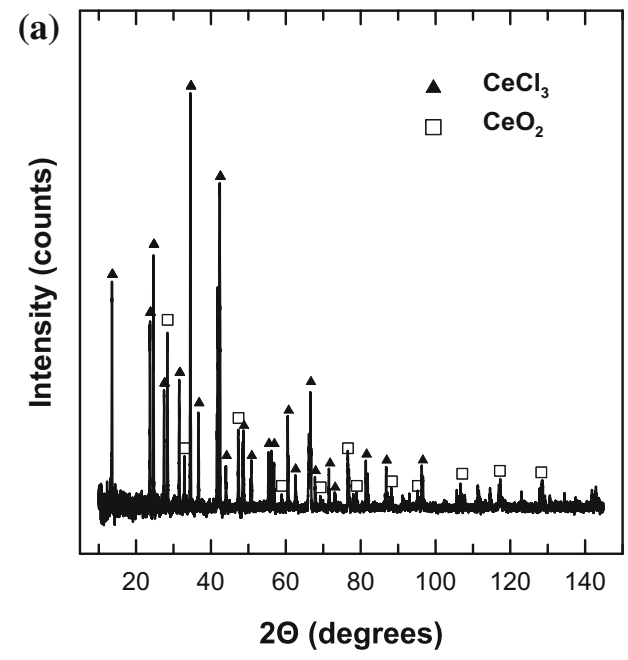

Figure 8 shows the XRD pattern for the lowest \% conversion sample for the cerium oxide carbochlorination study before and after the water leach. The XRD pattern of the before-leached sample shows primarily cerium oxide peaks with a few peaks in between $10^{\circ}$ and $40^{\circ}$ that may indicate the presence of the cerium chloride phase. The possible cerium chloride peaks are no longer observed in the XRD pattern for the after-leached sample; only the peaks for cerium oxide remain. Figure 9 shows the XRD patterns for the highest $\%$ conversion sample before the water leach. The XRD pattern for the before-leached sample shows that cerium chloride peaks are much more prevalent and intense when compared to the patterns presented in Fig. 8. The XRD pattern for the after-leached sample in Fig. 9 shows that cerium oxide is the main phase present and possibly some peaks that correspond to the cerium oxychloride phase. In both the lowest and the highest $\%$ conversion samples, the XRD patterns indicate that the cerium chloride was effectively removed through the water leach.

Figure 10 shows the XRD patterns for the lowest \% conversion sample for the neodymium oxide carbochlorination study before and after the water leach. The XRD pattern for the lowest \% conversion sample before the water leach shows that the sample consisted of neodymium oxychloride. The XRD pattern for the lowest \% conversion sample after the water leach indicates that the predominate phase was no longer the neodymium oxychloride but rather a hydrated form of the neodymium oxychloride. Neodymium compounds have a greater tendency to hydrate, and so this change in phase is mostly due to the water leaching process [12]. The hydrated neodymium oxychloride phase occurred in the after-leached samples for all of the test samples that were run at the low- and medium-level temperatures. The presence of this hydrated phase may have caused inaccuracies in the \% conversion values calculated 
Fig. 10 XRD patterns for the the neodymium oxide carbochlorination experiments. a Before the water leach and b after the water leach lowest \% conversion sample in
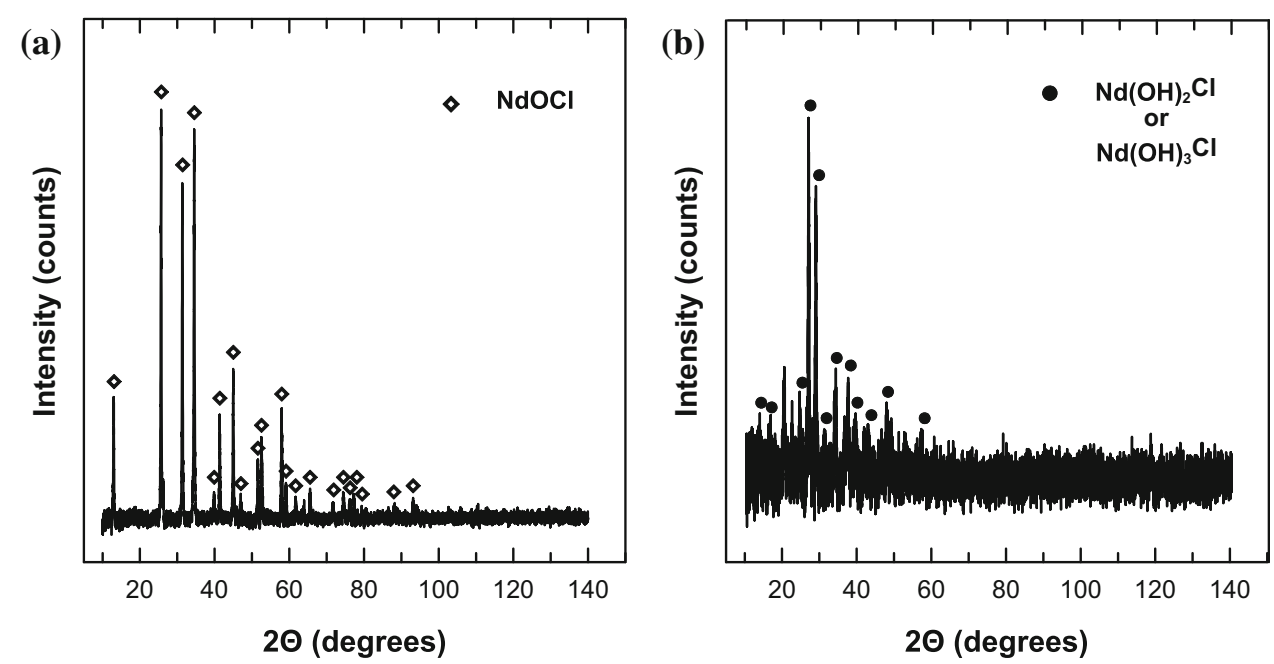

Fig. 11 XRD patterns for the highest \% conversion sample in the neodymium oxide carbochlorination experiments. a Before the water leach and b after the water leach

Fig. 12 Equilibrium composition plots for the carbochlorination process utilizing $100 \%$ carbon and $100 \%$ chlorine gas according to Eqs. 1 and 2 for a the cerium oxide system and $\mathbf{b}$ the neodymium oxide system
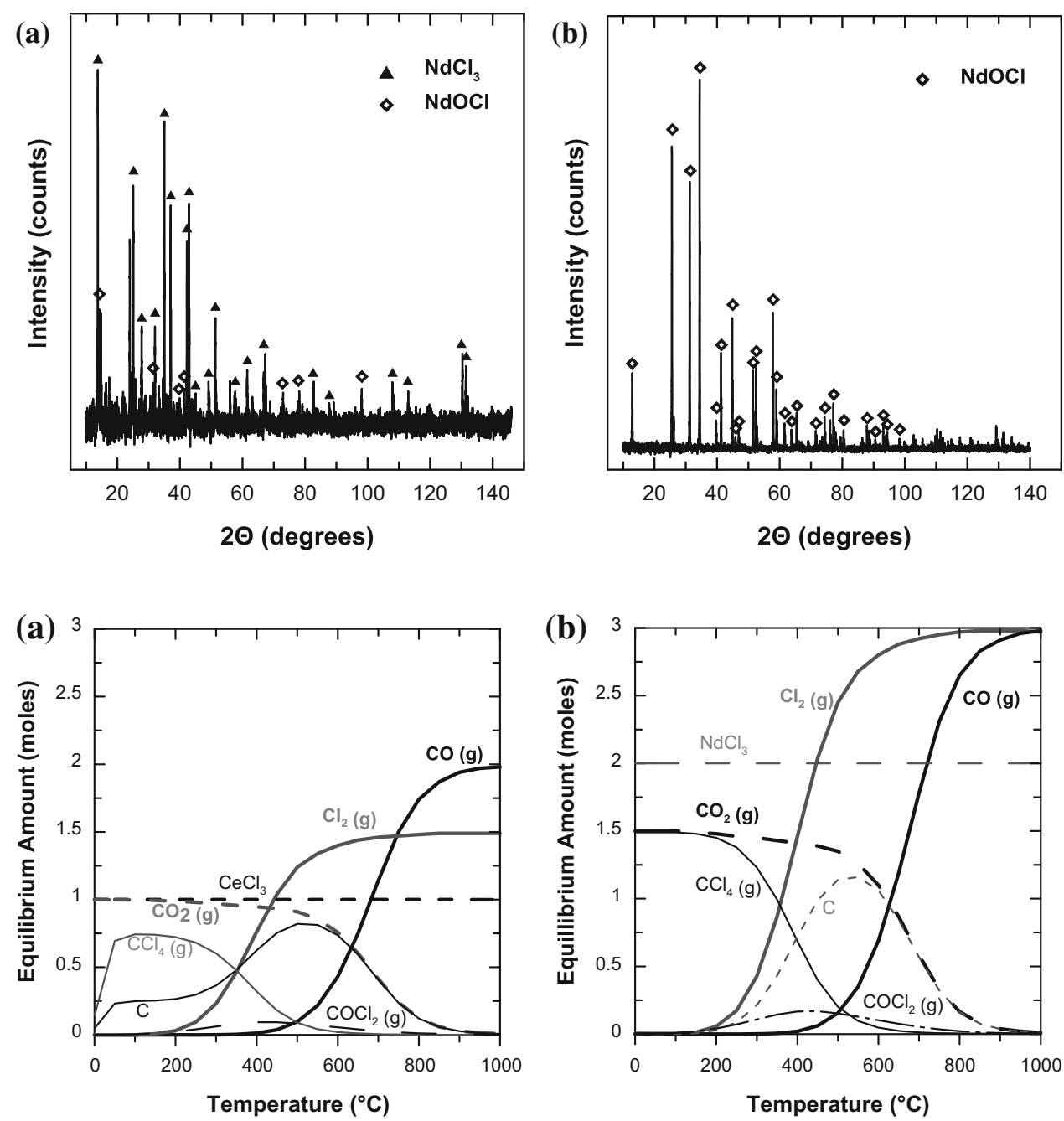

for these tests due to the added mass of the moisture in the after-leached mass. The after-leached masses for all of the optimization experiments performed at low- and mediumlevel temperatures were multiplied by the ratio of $\mathrm{NdOCl}$ to $\mathrm{Nd}(\mathrm{OH})_{3} \mathrm{Cl}$ to correct for the presence of the hydrated phase.

Figure 11 shows the XRD patterns for the highest \% conversion sample for the neodymium oxide 
carbochlorination study before and after the water leach was performed. In this case, the XRD pattern shows that both neodymium chloride and neodymium oxychloride were present in the sample before the water leach, but only the neodymium oxychloride phase remained in the sample after the water leach indicating that the water leach was also effective in removing the neodymium chloride. XRD analysis did not show a hydrated neodymium oxychloride in the after-leached samples for the tests that were run at the high testing temperature.

The results of this study may indicate that the reaction kinetics at lower temperatures are dominated by temperature and not the gas availability when there is excess carbon and chlorine gas content. But, under higher reaction temperatures, the kinetics of conversion are much faster and require gas availability. Therefore, at higher temperatures, the degree of reaction is also influenced by carbon and chlorine gas content.

The results from this study may also point to the importance of intermediate gases such as phosgene $\left(\mathrm{COCl}_{2}\right)$ and carbon tetrachloride $\left(\mathrm{CCl}_{4}\right)$ for conversion at lower temperatures. Figure 9 shows equilibrium plots generated by HSC Chemistry 5.1 for the carbochlorination process where $100 \%$ excess carbon and $100 \%$ chlorine gas according to Eqs. 1 and 2 were used as inputs for both the cerium oxide and neodymium oxide systems. Along with carbon dioxide and carbon monoxide gases, the equilibrium plots also show that phosgene and carbon tetrachloride gases are thermodynamically favorable at lower temperatures. The excess chlorine and carbon content helps in the formation of these intermediate gases, both of which have been proposed as the actual reducing gases in the carbochlorination reaction. Figure 12 shows that larger quantities of phosgene and carbon tetrachloride are more thermodynamically stable at lower temperatures in the neodymium oxide system than in the cerium oxide system. Generation of larger quantities of these intermediate gases could be a possible explanation for the observed greater dependence on carbon at the lower temperatures for the neodymium oxide carbochlorination process versus the cerium oxide carbochlorination process.

It should be noted that this study did not fully optimize the necessary chlorine gas content as the carbochlorination experiments were performed in an unstirred system, but the process time and temperature were optimized under excess reactant inputs.

\section{Conclusions}

The major conclusions established from the present investigation are as follows:
(1) Conversion of cerium oxide and neodymium oxide to their respective chlorides can be accomplished through the carbochlorination reaction.

(2) Generation of rate curves showed that both of the carbochlorination reactions had an optimal reaction time of around $4 \mathrm{~h}$.

(3) The optimization studies showed that all of the process parameters evaluated were important for maximum degrees of reaction with temperature being the most significant parameter for both the cerium oxide and neodymium oxide carbochlorination reactions.

(4) The amount of carbon present for the reaction played a much larger role in the reaction for the neodymium oxide carbochlorination than the cerium oxide carbochlorination.

(5) The oxychloride phase was also much more prevalent in the neodymium oxide carbochlorination experiments than the cerium oxide carbochlorination experiments.

Acknowledgments The authors would like to acknowledge the financial support received from the USDOE Critical Materials Institute Energy Innovation Hub.

\section{References}

1. Hatch GP (2011) Critical rare earths: global supply \& demand projects and the leading contenders for new sources of supply. Technology Metals Research

2. Ames National Laboratory, web (2013) The Critical Materials Institute, US Dept. of Energy

3. Schüler D, Buchert M, Liu D (2011) Study on rare earths and their recycling. Öko-Institut 49:30-40

4. Gupta C, Krishnamurthy N (1992) Extractive metallurgy of rare earths. Int Mater Rev 37(5):237-279

5. Gupta C, Krishnamurthy N (2005) Extractive metallurgy of rare earths. CRC Press, Boca Raton

6. Esquivel M, Bohé A, Pasquevich D (2003) Carbochlorination of samarium sesquioxide. Thermochim Acta 403(2):207-218

7. Pasquevich L, Gamboa J, Caneiro A (1992) On the role of carbon in the carbochlorination refractory oxides. Thermochim Acta 209:209-222

8. Outokumpu Research (2005) HSC chemistry 5.1. Pori, Finland

9. World Chlorine Council, web (2011) Chlorine safety scrubbing systems, 1st edn. pp 4-47

10. Seidell A, Linke W (1952) Solubilities of inorganic and metalorganic compounds, 4th edn. Princeton, van Nostrand

11. Levenspiel O (1991) Chemical reaction engineering, 3rd edn. Wiley, New York

12. Bosco M, Fouga G, Bohé A (2012) Kinetic study of neodymium oxide chlorination with gaseous chlorine. Thermochim Acta 540:98-106 